\title{
Art Across Borders: Dislocating Artistic and Curatorial Practices in the Barents Euro-Arctic Region
}

\author{
Holger Pötzsch, UiT Tromsø
}

Version accepted for publication. Published article can be accessed here: http://www.tandfonline.com/doi/full/10.1080/08865655.2015.1036099\# $\underline{\text { abstract }}$

\begin{abstract}
$\underline{\text { Abstract }}$
The present article investigates the role of artworks in processes of bordering in the Barents Euro-Arctic Region. Drawing upon a neo-formalist framework, it firstly analyses works that were exhibited during the X-Border Art Biennial to identify disruptive potentials vested in the artistic pieces' formal properties, before it, secondly, addresses potential performance effects of these works and of the curatorial decision to distribute exhibition space across three cities in Sweden, Finland, and Russia. I argue for an ambivalent role of artistic and curatorial practices that have the inherent potential to articulate opposition and de-familiarize established frames for perception and cognition, and at the same time inhere the capacity to reinforce regimes of exclusion and facilitate processes of commodification and capitalization.
\end{abstract}

Keywords

Biennial, X-Border Art Event, neo-formalism, bordering, Barents Euro-Arctic Region, art, borderscape

7039 words (excl. references, acknowledgement, abstract, and image captions) 


\section{Introduction}

In an article that argues for an intrinsic interconnection between artistic expressions and processes of bordering, Schimanski and Wolfe (2013) show how Morten Traavik's work Borderlines (2011) - an installation that displaces actual, physical border posts from the Norwegian-Russian border into the centres of the Norwegian towns of Oslo and Kirkenes - at once functions as a disruptive intervention, and becomes subservient to contemporary trends of capitalization and commodification. The authors write that Traavik's work both "defamiliarize[s] the border and the lives of the public" (241), yet also "becomes part of an on-going process of 'place branding' the town [of Kirkenes] as both a border town and a site of artistic innovation and consumption" (240). This fundamental ambivalence at the heart of artistic expressions and curatorial practices and its relation to state borders is the main focus of the present article.

Through a reading of two artworks exhibited at the 2013 X-Border Art Biennial that was arranged in Luleå (Sweden), Rovaniemi (Finland), and Severomorsk (Russia), the present article will analyse how Tokio Maruyama's Geographical Imagination and Strijdom van der Merwe's Diaspora invite for a dehabitualization of received ways of seeing and enacting borders. Subsequently, critical attention will be directed to the embedding of the Biennial in socioeconomic and political frames that tacitly predispose artistic and curatorial practices. The article argues for the significance of cultural expressions and dissemination mechanisms for processes of bordering in the Barents Euro-Arctic Region. Initially, however, a theoretical and methodological framework that allows for a better understanding of how works of art impact upon the politics and everyday practices of bordering needs to be introduced.

\section{Border studies beyond the state}

What is a border? This question has been repeatedly posed in the discipline of border studies and responses vary from narrow conceptualizations of the border as a political dividing line between sovereign nation states interacting on a global arena (O’Dowd 2010), and wider understandings that posit the border as the dynamic effect(s) of dis-located socio-cultural negotiations and performances of difference (Schimanski \& Wolfe 2013; Parker \& VaughanWilliams 2009; Johnson et.al. 2011; van Houtum 2012; Rumford 2012). In the latter understanding, borders are not confined to concrete territorial dividing lines, but disperse and form complex and multi-modal borderscapes (Brambilla 2010, 2014; Rajaram and Grundy-Warr 2007; Schimanski 2014).

Such a widened perspective enables a conception of the border as a zone that facilitates both encounters and division (Rovisco 2010), and as a potential resource providing orientation in ambiguous socio-cultural terrains (Perkins and Rumford 2013). Van Houtum and Naerssen (2002) introduce the term bordering to highlight performative and inherently productive aspects of regimes and practices of in/exclusion, while Perkins and Rumford (2013) refer to a "vernacularisation" (270) of borders and border research to account for the increased significance of day-to-day practices. Their approach makes borders conceivable as not only a limiting frame, but also a resource that provides orientation in ambiguous terrains. I will draw on such reconceptualisations and, through focus on the role of aesthetic expressions in the bordering process, 
contribute to a "multiperspectival study of borders" (887) recently called for by Rumford (2012).

According to Brambilla (2014), borders are multidimensional constructs that emerge through a constant "interweaving of a multiplicity of discourses, practices, and human relations “ (8). In this perspective, the border emerges as a partial and temporary objectification of relevant differences that sediments spatially and is subjected to constant negotiations and renegotiations in and through the constrained every-day practices of socio-culturally situated subjects. Functioning as an "operative fiction" (Schmidt 2008: 67), the border is, as such, neither subjective, nor objective, but becomes conceivable as an emergent and dynamic, inter-subjective construct. This article focuses on the role of cultural expressions in the constant formation and re-formation of such inter-subjective border constructs and puts particular emphasis on the interplay between material form and cognitive as well as perceptual frames.

The article will introduce two ways through which works of art can impact upon contemporary processes of bordering. Firstly, drawing upon a neo-formalist framework (Thompson 1988), it is argued that aesthetic objects can have a dehabitualising effect on established cognitive frames and schemata that tacitly predispose day-to-day practices including such connected to processes of bordering. In this perspective, art gains a political dimension in that it has the potential to undermine the naturalized systems of thought and belief that tacitly frame the institutionalized practices upholding contingent regimes of in/exclusion. Secondly, a more activist approach to border art (Amoore and Hall 2012; Vukov and Sheller 2013), serves to show how artistic interventions in the socio-technological and material infrastructure of borders can entail directly political "performance effects" (Amoore and Hall 2010: 305) that subvert practices of in/exclusion by actively improving the permeability of borders.

The present article will, firstly, introduce a neo-formalist approach to art and exemplify the potential impact of aesthetic objects on the cognitive level of bordering processes with reference to a selection of works exhibited at the 2013 X-Border Art Biennial. Secondly, this formal perspective will be contrasted with an assessment of the directly political performance effects of the biennial's curatorial practice that distributed the event across the Barents region to three different cities located in Sweden, Finland, and Russia.

\section{Bordering culture: Neo-formalist approaches to border art}

This subheading entails two potential meanings - culture borders and, to be able to emerge as a meaningful unit in the first place, culture is bordered. This section will throw light upon the mutually constitutive relationship between cultural expressions, perception and cognition, and the formation of subjectivities. As such, the role of cultural expressions in processes of bordering can be critically addressed.

In his Invitation to Cognitive Sociology, Zerubavel (1997), argues that one experiences the world "not only personally, through [one's] own senses, but also impersonally, through [one's] membership in various social communities" (7; emphasis in original). Such "thought communities" (9; emphasis in original), as 
Zerubavel terms them, are formed through systems of conventions that tacitly color and frame individuals' perception and cognition, and thereby influence their performances. These conventions - tacit interpretative, perceptual, and performative schemata - are reiterated in culturally significant foundational paradigm scenarios that are conveyed and reproduced in for instance cultural expressions. Zerubavel terms these systems of conventional schemata and paradigm scenarios "social mindscapes" (8) and locates them in the middle of a scale between subjective inner worlds and an objective physical world. The border as an "operative fiction" (Schmidt 2008) at once emerges as the contingent product of, and an important precondition for, such social mindscapes that are negotiated at an inter-subjective level.

Recent advances in the field of cultural psychology can improve an understanding of the processes through which individual identities are formed and negotiated with reference to cultural expressions and social mindscapes. Showing the significance of intersubjective cognitive schemata, scripts, and frames for the formation of "socio-cultural subjectivities", for instance Kirschner (2010) argues for the inherent instability and processuality of selfhood as "an emergent level of an all-encompassing biosocial reality" (771). As such, identities emerge as contingent and "constitutively intertwined with their cultural surround" (Kirschner \& Martin 2012: 4). Borders provide the necessary orientation that allows for a temporary stabilization of these individual identities within the frames of particular social mindscapes.

When perceived form the perspective of cognitive sociology and cultural psychology, the border is at once the contingent result of, and the conditioning frame for, complex processes of identity formation. Cultural products have the inherent potential to influence these processes in either reinforcing or challenging habitualized ways of seeing, thinking, and ultimately acting. A neoformalist approach enables an assessment of the function of cultural expressions in these contexts and makes possible a better understanding of the role of art and popular culture in the constant formation and reformation of contingent regimes of in/exclusion.

In their study on the role of aesthetics in the negotiation and functioning of borders and borderscapes, Schimanski and Wolfe (2013) assert the significance of the sensible in general, and artworks in particular, for processes of bordering. Drawing upon the thought of Victor Shklovsky, they argue that the work of art has the inherent potential to insert "difference into our ideologically fixed versions of reality, partly by delimiting art from the everyday, partly by deforming experience" (241). According to them, "[t]his defamiliarisation gives it [art] its critical potential" (241) and enables a political role of cultural expressions also in relation to contemporary regimes and practices of bordering.

Thompson (1988) employs the same neo-formalist framework based on the ideas of Shklovsky to investigate the de-habitualizing potential of artworks in relation to accustomed frames of perception and cognition. Thompson writes: "Art defamiliarizes our habitual perceptions of the everyday world, ideology [...], of other artworks, and so on by taking material from these sources and transforming them." This transformation, she continues, "takes place through their placement in a new context and their participation in unaccustomed formal patterns" (11). While effective for a certain time, Thompson writes, these dehabitualizing potentials will eventually become familiar, and the subversive, challenging effect of such artworks fades and "ebbs away" (11). 
Art is always received in a certain context that colours and predisposes possible forms of engagement, including the (de)activation of particular schemata and potential (de)habitualizing effects. To be able to account for such a situatedness of reception, Thompson (1988: 21-25) introduces the term background. Writing about film as an art form, she distinguishes background in relation to a) the everyday world including historical situation, politics, and everyday practices and habits, b) other artworks to which the work under scrutiny is connected to through generic form or intertextual references, and c) implicit or explicit purposes the work is put to by either the artist (director), curator, critics, or the general public. In critically attending to these various backgrounds, the analyst can tease out meaning potentials inherent in the given formal structure of the work.

Within such a neo-formalist framework, reception emerges as the contingent result of interactions between artworks' formal properties, socio-political and historical backgrounds, and established cognitive and perceptual schemata. As such, neo-formalism does not analyse "a set of static formal structures [...], but rather, a dynamic interaction between those structures and a hypothetical viewer's response to them" (Thompson 1988: 30). In doing so, the artwork can, potentially, either reinforce or challenge established cognitive patterns and habitual frames, and it can either successfully play into or subvert hegemonic backgrounds. As David Bordwell (quoted in Thompson 1988: 30) expresses it, "[a]rt may reinforce, or modify, or even assault our normal perceptual-cognitive repertoire". In these potentials to reinforce or assault established frames for cognition and perception lies the core of a political function of art in a neoformalist perspective. ${ }^{1}$

In an article on what he terms a Classificatory Imagination, Beer (2013) has argued, that "when understanding cultural boundary drawing we need to appreciate the wider processes of classification [...] in the passage of everyday practices" (149). The combination of cognitive sociology, cultural psychology, and neo-formalist analysis suggested here, provides a terminology that enables a description and systematization of the socio-cultural, material, and mental frames that predispose everyday acts of seeing and thinking to either reiterate, or challenge, pre-established borders and the regimes of in/exclusion these entail. As such, the present framework allows for a methodologically sound explication of the formal means through which works of art might challenge and change what Rancière (2010) terms a "distribution of the sensible" (36) stabilized by a regulatory regime of police. The following analysis of two artworks exhibited during the 2013 X-Border Art Biennial will serve to highlight such a formal basis for a tacit framing of perception and cognition.

\footnotetext{
${ }^{1}$ Of course, a neo-formalist approach is only one way of addressing the impact of art on the spectator including the analyst. As for instance Greve (2015) argues with reference to literature, art does more than play upon and potentially challenge particular cognitive and perceptual schemata. According to her, attention to an artwork's peculiar concern provides a suitable approach to singular interpretation that is distinct from the present study's attempt to explain how works of art invite particular responses at a general level.
} 


\section{Art across borders: The X-Border Art Biennial²}

In 2013, the world's northernmost international art biennial, the Luleå Art Biennial, for the first time expanded its scope across the Barents region combining physical exhibition spaces in Sweden, Finland, and Russia with a virtual online presence on an own website and blog that contain general documentation, additional artworks, comments, and interviews with participating artists. This way, the thematic frame of the X-Border Art Biennial that focused on "boundaries, identity, cultural diversity and knowledge in a time of globalization" (X-Border Art Biennial website 2013), was successfully supplemented with a curatorial practice that implied a regional focus and opened for interesting contemplations pertaining to the relation between works of art and a politics of borders in the Barents region.

The Barents Euro-Arctic Region includes the Northern areas of Norway, Sweden, Finland, and Russia. During the cold war, the border between the NATO country Norway and the Soviet Union was heavily fortified and virtually impossible to cross. With the end of the militarized East-West divide, however, also the permeability of the border increased leading to various forms of economic, political, and cultural cross-border exchange that was often based on a deliberate reactivation of long historical traditions of cooperation between the areas arbitrarily divided between opposing power blocks (Nielsen 1994, Hønneland 1998). Established in 1993 with the signing of the Kirkenes declaration, the Barents Euro-Arctic Region (BEAR) consists of formal bodies at both an intergovernmental (Barents Euro-Arctic Council) and a regional (Barents Regional Council) level that facilitate cross-border activities and exchange across various sectors.

Today, the Norwegian-Finish-Russian borderland is at once the location of a tightly controlled and monitored external Schengen border, and the site of inherently cooperative governmental and people-to-people cooperation that fosters social, economic, political, and cultural interconnections between the countries. BEAR has been widely perceived as a success and as facilitating required economic, societal, and political transitions after the demise of the Soviet Union. Most recently, however, economic and political initiatives have been somewhat downgraded leaving an often culturally inflected people-topeople cooperation as the main cornerstone of continued cross-border activities (Hønneland 2010).

As Schimanski (2014) has noted, the Barents region emerges as a complex borderscape where identities, connections, and divisions are constantly negotiated in and through not only economic and political performances, but equally by means of cultural expressions. The material regimes of borders and the practices of in/exclusion they invite are enmeshed in a cultural domain and vernacular day-to-day performances that inhere the capacity to either reinforce,

\footnotetext{
${ }^{2}$ I conducted fieldwork at the X-Border Art Biennial in Rovaniemi, Finland June 14-20, 2013. I observed the process of planning and setting up artworks at two exhibition spaces and three outside locations in and around town, and conducted a total of 16 semi-structured interviews with artists and curators. My gratitude to the EUBORDERSCAPES-project for funding the stay and to the curators and artists in Rovaniemi for hosting me and supporting me with my investigations.
} 
or challenge and subvert, border mechanisms and procedures. The Northern borderscape, as such, becomes conceivable as "a network held together by strategies of rhetorical, symbolic and discursive signification" that enables exclusionary division as well as inclusive cooperation - "the borderscape can be an ambivalent space of both power and resistance" (Schimanski 2014).

I will now move on to an analysis of specific artworks that were exhibited in Rovaniemi to tease out some of the formal elements enabling a challenge of established border-related schemata and scenarios. It has to be noted, that very few of the displayed works directly addressed issues connected to the Barents Euro-Arctic region. A majority treated the issue of borders and boundaries at a global or conceptual level. Claudia Chaseling's large-scale wall painting and multimodal installation Murphy the Mutant, for instance, critically highlights the devastating consequences of cross-border nuclear legacies caused by the use of depleted uranium ammunitions. At the same time, her active incorporation of the exhibition space enables a productive questioning of the border between artworks and their immediate context of reception. Ulrica Beritsdotter's Lost in Translation, on the other hand, draws upon a background composed of an iconic film sequence from Kubrick's 2001: A Space Odyssey (1968) to invite critical contemplations regarding the ultimate limits of human rationality, and its intrinsic connection to various forms of violence, while Lise Bjørne Linnert's Fences actively intervenes in tacit and mundane every-day bordering practices by cutting holes in fences and railings before marking the opening with red thread.

In the following, attention will be directed to two artworks particularly suited to challenge tacit patterns of cognition and perception underlying contemporary processes of bordering, Tokio Maruyama's Geographical Movement and Strijdom van der Merwe's Diaspora, before the article turns to the potential performance effects of the biennial's cross-border curatorial practice in relation to the contemporary Barents borderscape.

\section{Geographical Movement (Tokio Maruyama)}

Maruyama's artwork Geographical Movement was developed on the basis of the observation by the artist that, when drawing a straight line through all the three locations of the X-Border Art Event and extending it over the entire globe, it approximately crosses through the Japanese town of Fukushima - site of the nuclear incident in the aftermath of the 2011 tsunami. This coincidence triggered contemplations concerning the inherent fragility of the earth and of the various life forms it sustains, and lead to a work that questions the continued relevance of state borders in times of increasingly globalized threats.

Maruyama's work consists of a large artificial wall set up in the exhibition space. On either side of this wall the artist painted a world map, before he started to gradually drill holes into the wall in a pre-defined pattern. On the exhibition's opening night Maruyama drilled a human shape in the middle of his world map and subsequently climbed through the by then perforated wall thereby deliberately destroying a significant portion of his work. The entire process of painting, destabilisation, and destruction was documented with a photographic camera attached to a tripod and standing at a fixed distance from the wall. 


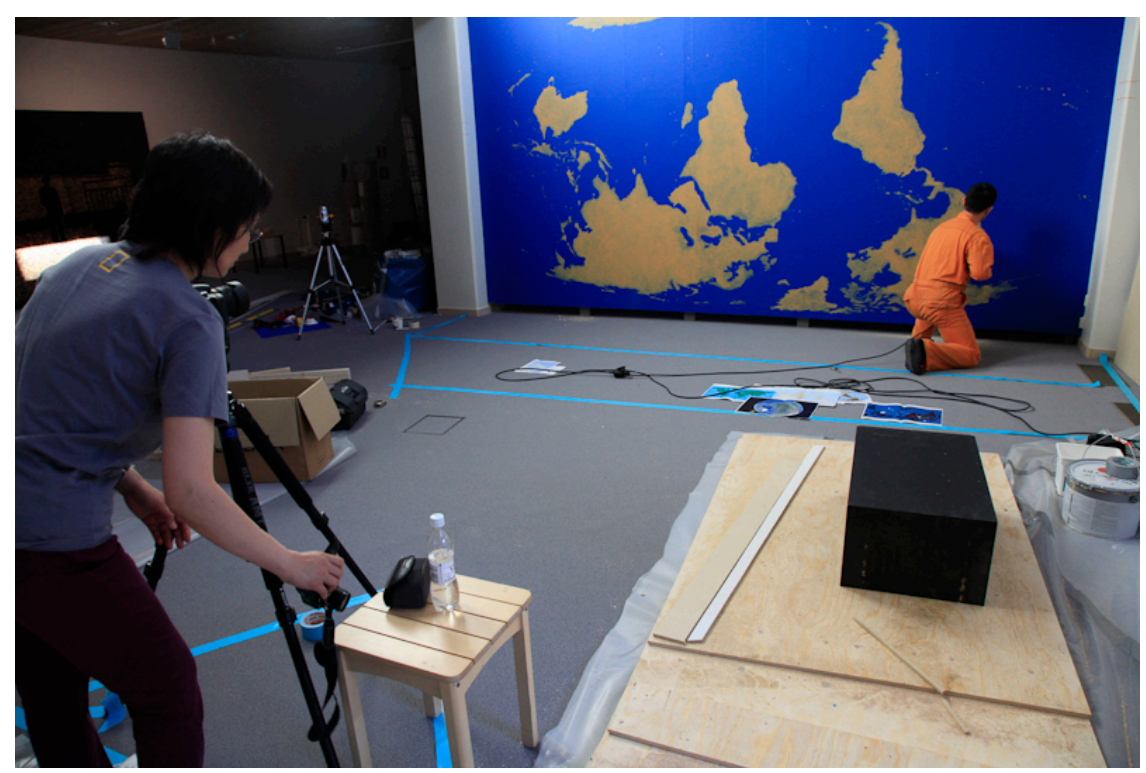

Image 1: Documenting the gradual perforation of Maruyama's world wall (courtesy Maruyama).

Geographical Movement functions at a variety of registers that combine physical objects with performance and electronic documentation. Processes of preparation and construction prior to the opening night become integral components of the artwork as a whole that, through its subsequently performed, partial destruction, is disconnected from the physical object that often stands as a static representation for the potential impacts and effects of cultural expressions. The de-familiarising potential of Maruyama's work is intrinsically connected to the pre-determined, yet dynamic perforation, and the subsequent, attuned destruction. Without knowledge of this crucial background, the implications of the work for border-related cognitive schemata cannot be fully assessed.

When observing Maruyama while he was setting up his work, ${ }^{3}$ one could bear witness to the gradual emergence of seas and continents on a large wall that eventually fused to form a meticulously accurate world map. In a second phase the artist started to drill holes into this map. This activity was conducted in a pre-established, almost ritualized fashion. Maruyama would take up the drill, walk toward a folder that was placed on the ground in front of the wall containing a sketch of his map, look at it for a moment, focus on the wall, approach it slowly, and drill a series of holes at particular, apparently accurately pre-determined spots. This structured sequence of actions was repeated for days, and was only interrupted by the occasional taking of pictures with the fixed camera. As will be explained below, this sequencing of actions is a decisive formal property of Geographical Movement as a performative art object and points to its critical potential enabling a de-habitualisation of accustomed ways of using and producing maps.

Upon request, Maruyama explained the logic behind his apparently strange conduct. Each of the initial holes, he had drilled into the world wall represented a nuclear test site, power plant, or waste deposit. He had marked all these sites

${ }^{3}$ I had the chance to follow the setting up of Maruyama's work during fieldwork in Rovaniemi, Finland, June 14-20, 2013. 
on his sketch and slowly perforated the planet in consecutive historical order. As such, starting with a hole in northern New Mexico, USA, that represented the first nuclear test in human history in 1945 and quickly moving on to Hiroshima and Nagasaki, Maruyama drilled his way through mankind's nuclear history, thereby visibly, and uncannily, marking the planet with the increasingly salient scars caused by these activities. He interrupted his course of action after each year to take a picture documenting the gradual fragmentation of the planet.

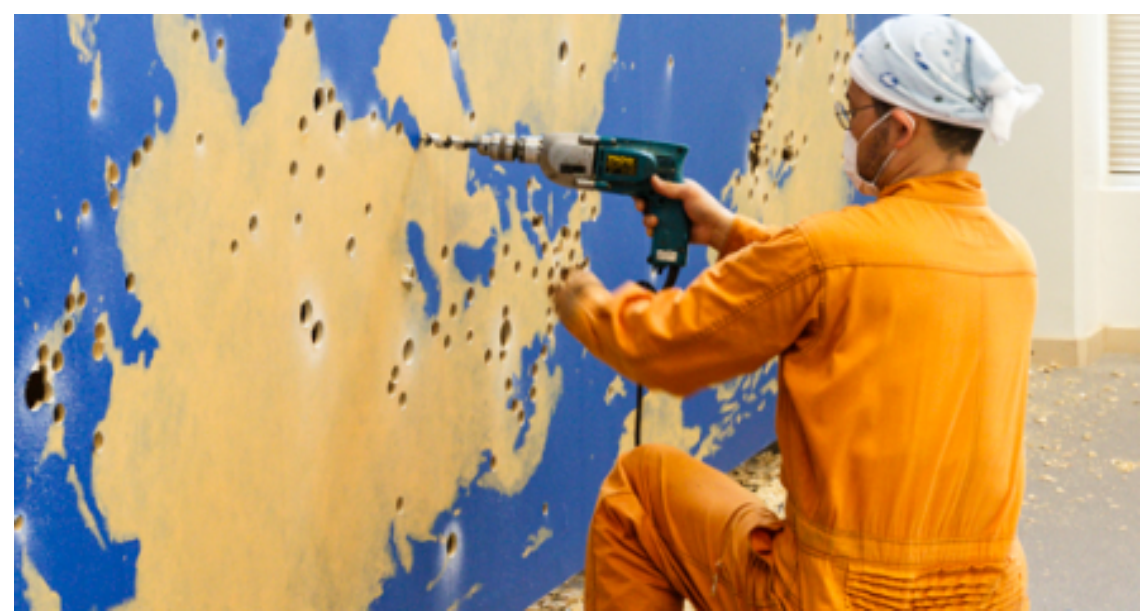

Image 2: Perforating the planet (courtesy Maruyama).

When perceived in this perspective, the final breaking through the Earth's crust and the severe damage to the world wall this act entailed - acquires shocking qualities that continue to haunt the witnessing spectator even though the physical object partly lays in shatters. However, knowledge of the artist's immediate purpose and the context of preparation and documentation emerge as a necessary background for a full appreciation of the work. This is particular salient for a border-related reading of Maruyama's work.

In Geographical Movement Maruyama re-appropriates an apparently familiar object - a world map -, gradually estranges its meaning potentials, and increasingly frustrates customized patterns of use and perception. His artwork leads attention away from the arbitrary lines and colored patches signifying nation states and subverts the apparently self-evident significance of geographical structures as salient features of maps. In making the result of human nuclear practices the basis for a re-mapping of a borderless world, Maruyama's work de-familiarizes accustomed patterns of use and challenges scopic regimes that prove incapable of perceiving the Earth as a shared and fragile global place. The destruction of his work on the opening night, then, sets a performative punctum that powerfully reiterates the uttermost consequence of a continued neglect of shared nuclear and other threatening cross-border legacies.

\section{Diaspora (Strijdom van der Merwe)}

Van der Merwe's open-air installation is maybe the most directly border-related of the works displayed in Rovaniemi. Diaspora consists of three large rocks placed on a lawn in a residential area between the city's centre and an adjacent river. The boulders are set up as the corners of an irregular triangle and to each of them words in different languages are attached that anchor the work to a discourse of political borders and human migration. On one side of each stone, 
the lawn had been removed to indicate a trace left by the apparently once moving object.

According to the artist, ${ }^{4}$ the boulders he used, though apparently solid and fixed, serve to indicate mobility as they had been carried from remote mountains to their location close to Rovaniemi during the ice age. This, he continues, reveals an inherent arbitrariness and temporality of human borders when perceived from the perspective of a historical long durée. The ultimate contingency of human boundaries and divisions becomes palpable precisely through such natural movements and dis/re/placements in the course of time. As such, van der Merwe asserts, these stones become conceivable as components of larger processes that constantly unfold around us and remain unconcerned with human categories and differentiations.

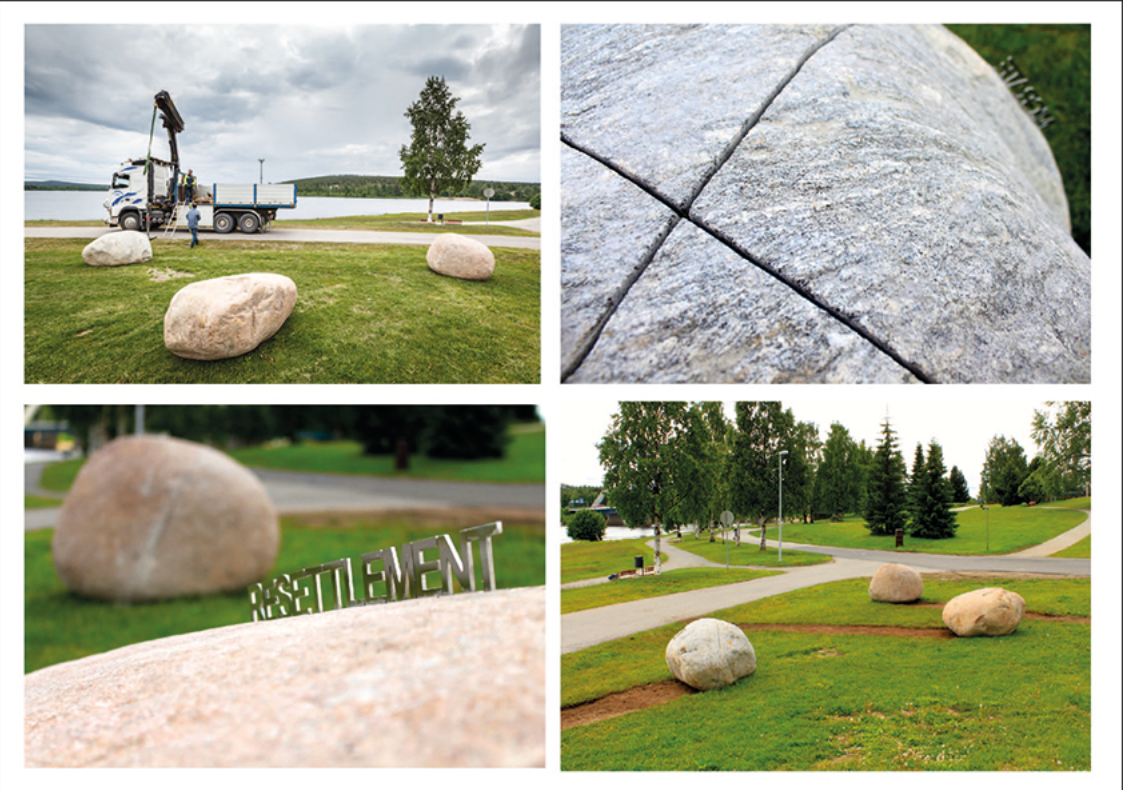

Images 3-6: Rescaling borders and mobility in geographical time: van der Merwe's Diaspora (courtesy van der Merwe).

Through the formal device of the apparent trace, van der Merwe's work creates the impression of a merely momentarily halted movement, a freeze frame arbitrarily cut out of more complex and enduring trajectories and developments. This way, Diaspora enables a de-habitualisation of established perceptional and performative patterns that, customarily, treat rocks as signifiers of solidity and durability exemplified by such common uses as gravestones or boundary stones. In reasserting the movability of apparently immobile entities, van der Merwe's installation, thus, also entails a tacit challenge to sedimented and naturalized structures and practices that selectively limit human capacities to migrate and cross borders. As such, the application of a different historical scale reveals the ultimate contingency, and indeed arbitrariness of present days borders.

Besides national and other borders interfering with migration and movement, Diaspora deals with a second fundamental boundary that structures and

\footnotetext{
${ }^{4}$ The interview with van der Merwe referenced in this section is accessible here: http://www.youtube.com/watch?feature=player_embedded $\& v=b A C P q 7 x S x e U$ (visited February 19, 2014).
} 
predisposes much of contemporary politics - the division between public and private space. This second division becomes accessible not so much through the work's content or overt theme, but through the peculiar artistic practice of landscape art. In embedding works of art in land- and cityscapes, artists make them a natural part of everybody's surround, and thereby at a fundamental level, common property. This artistic practice, as such, challenges the gatekeeping function of galleries, art critics, collectors, and curators, and re-inserts art into society at the very core of everyday life.

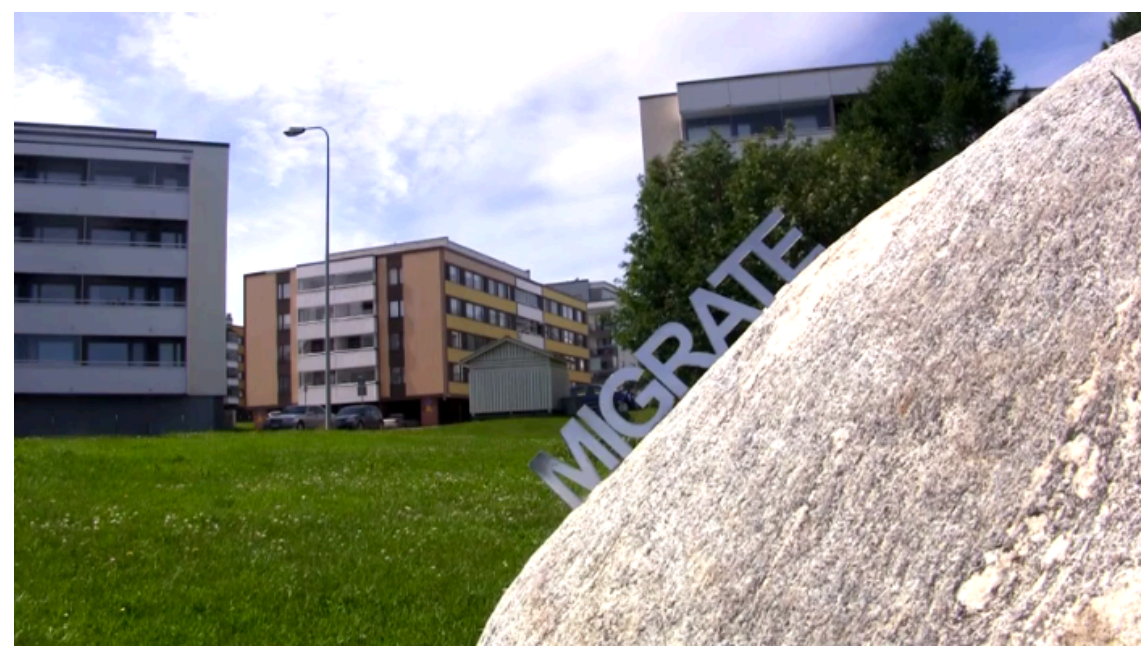

Image 7: Embedding art in public space (courtesy van der Merwe).

In a similar case of embedding, Buden (2006) has argued that the Homeless Project of Milovan Markovic, where the artist put large-scale sketch-banners containing parts of the life stories of homeless people at display in the central districts of such major cities as Berlin, Belgrade, or Tokyo, is not political due to the suppressed voices it publicly articulates, but by re-appropriating increasingly privatized and fragmented public space:

His [Markovic's] art becomes political not by its tendency, that is, in the intentional content of its public interventions, which is in the case of Homeless Project the act of making poor, marginalized and excluded people more visible, but on the level of seemingly pure artistic creation. What his art makes visible on this level is not social exclusion but the forgotten, or better, suppressed possibility of a different public space (8).

What Buden writes about Markovic retains its validity regarding the way through which van der Merwe's work not only reasserts a fundamental historical contingency of naturalized orders and borders, but also successfully reappropriates public space as a crucial arena for political deliberation and artistic intervention. As such, Diaspora successfully negotiates some of the ambivalences caused by an embedding of biennials in a global post-Fordist economy criticized by for instance Dimitrakaki (2012) or Kompatsiaris (2014), and emerges as what Paglen and Gach (2003) term a "positioned work" that is "self-reflexive about" the conditions of its own production and reception and that "incorporates those conditions [...] into the form of the work itself". 5

\footnotetext{
${ }^{5}$ Paglen and Gach's (2003) article is not paginated. It can be accessed here: http://www.joaap.org/1/TacticsWithout/index.html.
} 
As the readings above suggest, Maruyama's Geographical Movement and van der Merwe's Diaspora formally challenge established perceptual schemata and cognitive frames connected to mundane practices of bordering and classification at a general level. In inviting reconceptualisations of maps in the light of imminent global threats, and in addressing the ultimate historical contingency of borders and forms of mobility, the two works have the formal capacity to subvert established patterns of perception and cognition in relation to borders and boundaries. This way, they inhere a meaning potential that, when activated, can facilitate a reorientation of accustomed understandings and practices. However, to transform such formal potentials into concrete political effects, a widespread dissemination and availability of these works is required. ${ }^{6}$

Van der Merwe's Diaspora ensures such a continued accessibility through its direct embedding into a lived urban environment, this way also challenging the gatekeeping function of biennials, art fairs, and museums. The physical basis of Geographical Movement, on the other hand, is destroyed during the opening night. As such, for the latter work, the curatorial practice of electronic documentation and subsequent dissemination via the virtual exhibition space of the X-Border Art website ${ }^{7}$ becomes crucial for a transformation of formal potentials into public articulations with actual discursive and political effects.

In this respect, the availability on the X-Border Art website of images, artist interviews, a blog, and the exhibition catalogue constitute a viable departure point to ensure an increased longevity of the biennial's potential economic and political impacts. However, the failure to provide access to the sequence of images taken by Maruyama to document the gradual emergence and subsequent destruction of his world wall decisively limits the potentials of Geographical Movement to continuously affect its audience. As the reading above has argued, knowledge of the process leading up to the final climatic demolition constitutes a crucial background without which the whole meaning potential of Maruyama's work cannot sufficiently be teased out. As a consequence of this lack of availability of the electronic documentation, the work's disruptive potentials will probably remain unrealized.

A neo-formalist approach is well suited to account for the by and large conceptual engagements with borders and boundaries of several of the works exhibited during the X-Border Art Biennial. Specific practical impacts of the show in relation to the Barents borderscape, on the other hand, necessitate a second framework that not so much focuses on formal potentials for the creation of meaning, and the specific socio-technical conditions of dissemination, but that addresses the economic, cultural, and political frames within which artworks and exhibitions operate, and which are either reinforced or challenged

\footnotetext{
${ }^{6}$ Repeated statements made by artists I interviewed at the X-Border Art Biennial in Rovaniemi in June 2013 indicate a strong awareness for the subversive potentials of specific artworks, but at the same time revealed a lack of concern for public availability and dissemination of the articulated ideas. Only a minority of the interviewees had consciously included the biennial's virtual online exhibition space into the conceptualization of their artworks. As such, the intention of these works to influence politics and actualize the articulated challenges to naturalized exclusionary frames and positions might easily be undermined by a lack of public availability and access.

${ }^{7}$ The X-Border Art website can be accessed here: http://www.x-border.info/
} 
through artistic and curatorial practices. In this latter perspective, possible "performance effects" (Amoore and Hall 2010: 305) of the X-Border Art Biennial emerge as an important analytical focus.

\section{Curatorial and artistic practices at the borders of the Barents region}

Paglen and Gach (2003) have argued that contemporary artists often work on the basis of the "tacit assumption" that the role of art in society is "to provide a catalyst for dialogue, or to engage in a sort of consciousness-raising around [...] political themes". Revealing the drastically reduced efficacy of critical consciousness in relation to an increasingly cynical, mass media facilitated politics that tends to mould or bluntly disregard opposing majority views on key political issues such as climate change, the global war on terror, or austerity measures, the authors state that "for artists desiring to achieve material political effects, the goal of creating dialogue or raising consciousness frequently misses the mark". According to Paglen and Gach, the intellectual attitude of an artwork becomes less important than its concrete positioning in relation to dominant, economic, political, and societal power vectors. ${ }^{8}$

In contemporary visual art, the concrete socio-political position of a work is often dependent upon the practice of setting it up and displaying it at a particular location. The effects of the practices surrounding the work can either play into, or undermine and even reverse, the intended political message suggested by a particular content-based attitude. This line of thought becomes relevant in relation to the X-Border Art Biennial, as well. While the artworks predominantly deal with the issue of borders at a conceptual level, the curatorial decision to distribute exhibition spaces across three different countries and cities in the Barents region performatively positions the show at the heart of the Barents borderscape.

Through its spatial distribution across localities in Sweden, Finland, and Russia, and through its overtly political focus denouncing a self-referentiality of contemporary art, the X-Border Art Biennial apparently aligns to a current trend identified by Kompatsiaris (2014) that engages biennials and other large-scale art exhibitions in "explicit extra-visual dialogues with and within the public sphere" (76). According to Kompatsiaris, 'extra-visual' refers to an extension of the function of biennials beyond focus on artworks and towards an inclusion of seminars, guided tours, participatory online platforms, as well as various forms of political activism and empowerment. At the same time however, the author argues, art biennials have become an integral part of a "post-Fordist production model" (76) that functions within the frames of global capitalism. As such, in often facilitating consumption rather than contemplation, biennials and art fairs take part in the "co-optation and manipulation of esthetic regimes and cultural symbols" (76) to mold both artists and spectators into docile subjects implicitly

\footnotetext{
${ }^{8}$ In his own work, Paglen conducts a form of experimental geography - "a hybrid of empirical science, investigative journalism, political activism, and high end art" (Gustafsson 2013: 150) that aims at unveilling secret "black worlds" (Paglen 2010: 61) of state surveillance and oppression. See Paglen (2014) for his recent work that sets out to visualize the institutional architecture behind the NSA surveillance scandal.
} 
reproducing the very economic structures and relations of power they attempt to challenge and subvert through their artistic practices.

Dimitrakaki (2012) launches a similar criticism as does Kompatsiaris. Critically commenting upon an article by De Duve (2007), who suggests a return to classical notions of aesthetics and aesthetic judgment to make art more than "the name of a certain category of cultural commodities" (683), Dimitrakaki (2012) counters claims regarding an inclusive, participatory, and dialogical nature of contemporary art exhibitions and asserts a fundamental ambivalence regarding the political impact and socio-cultural effects of art shows. She argues that

[t]he exhibition form can be seen as a dissemination mechanism for radical work [...] that can broaden the public's exposure to this work's intentions and outcomes. Yet this dissemination mechanism also facilitates the collapse of pedagogy into consumption 'outputs', which is of course a ubiquitous feature of the postFordist knowledge economy" (317).

When perceived in this light, it becomes apparent that the relation between a work's attitude and its socio-political and economic positioning in the sense of Paglen and Gach (2003) is ambivalent and contradictory. As such, the practical consequences of artistic or curatorial performances might unwillingly reverse, or lead to a tacit co-optation of, an intended critical message.

Such an approach to the political role of artworks and exhibitions, however, can only partly be accounted for through a neo-formalist framework. Art not only facilitates a de-familiarisation of accustomed ways of seeing and thinking, but likewise entails "performance effects" (Amoore and Hall 2010: 305) that directly intervene in social, economic, and political practices. In relation to border art this leads to increased focus on artistic "counter-media practices that [...] interrupt or intervene in the assemblage of the border" to actively shape "countervisions, cracks, and subaltern spaces" (Vukov and Sheller 2013: 232), but also implies critical attention to possible unintended consequences that, at an underlying level of performance and practice, might serve to strengthen and reinforce, rather than undermine and challenge, established regimes of in/exclusion. ${ }^{9}$ Such a performative dimension of potential border-related effects retains its significance in relation to the curatorial decision to locate the $2013 \mathrm{X}$ Border Art Biennial in three different countries across the Barents region.

Given its location and size, and the moderate international attention it attracted, an economically inspired criticism such as the one launched by Dimitrakaki (2012) and Kompatsiaris (2014) appears unjustified when applied to the curatorial practices behind the X-Border Art biennial. Most of the artworks exhibited in Luleå, Rovaniemi, and Severomorsk were large-scale installations often with a significant performative dimension that were unsuitable for sale. As usual for biennials, and in contrast to art fairs, also the X-Border Art event was predominantly funded through public institutions. Even though the event

${ }^{9}$ Both Vukov and Sheller (2013) and Amoore and Hall (2010) refer to the Transborder Immigration Tool that was developed by the Electronic Disturbance Theatre at the University of California, San Diego, to electronically assist illegal crossings of the US-Mexican border as an example for an artwork with direct performative effects. For additional examples of performative border interventions at the US-Mexican border see for instance Walsh (2013: 975-979) and Weber (2012: 487-493). For a broad overview over US-Mexican border art see Amilhat Szary (2012). 
doubtlessly provided some national attention and possibly improved the standing of individual artists, or enhanced the involved cities' reputation as tourist destinations, a critical approach that focuses on this particular biennial's performative political impact has to look beyond issues of global capitalism. Rather, the question of how the event interfered with, and potentially tacitly reinforced, regimes of in/exclusion in the Barents region moves centre stage.

The X-Border Art Biennial was arranged at locations in Luleå (Sweden), Rovaniemi (Finland), and Severomorsk (Russia). The latter town, located at the coast of north-western Russia, contains vital military installations and, until today, remains closed for others than its own inhabitants. This fact increased the relevance of the location for a border-themed biennial, but at the same time entailed significant limitations for the activities of both curators and participating artists who worked at the Russian location. As such, several of the artists selected for display at the Severomorsk location had to send their works beforehand, and were not allowed to be present on site to oversee the setting up of their pieces. Others were allowed to stay for not more than 2-3 days.

Also artistic practices and the form and content of artworks were influenced by the strict controls imposed by the authorities in Severomorsk. As Lise Bjørne Linnert - an artist exhibiting in Severomorsk - put it in an interview I conducted with her, the subversive impact of her work was limited by bureaucratic rules and procedures:

The place where I wanted to leave [my artwork] would be at the harbour, $[\ldots]$ but they assigned me a place. I'm not allowed to choose. And, you know, normally I don't ask... I just... but because of this I had to tell them what my plans were, and now I am designated a spot, which was totally the opposite of what I was interested in.

Reflecting upon the effects of such limitations, the artist refers to her work in Severomorsk as "more of a decoration" before concluding: "And it's interesting, the story I write is then: this is what I was told to do, where I wanted to go somewhere else." Bjørne Linnert, however, also emphasized the positive effects of cross-border artistic practices and highlighted her continued ability to question and challenge the constraining frames imposed by the authorities in Severomorsk.

On the one hand, the X-Border art Biennial performatively enabled an increased permeability of the borders of the Barents region by facilitating an exchange of artists and curators between three nation states. As such, the performative dimension of the curatorial practice behind the exhibition facilitated bordercrossing activities and served, to some degree, to open up the secluded Russian city of Severomorsk. On the other hand, however, these border-crossing practices were conducted within the narrow frames set by state authorities to channel and control these activities. As the quote by the artist given above shows, a trade-off between artistic intentions and limiting state practices became necessary that at times threatened to performatively undermine the intended message to be conveyed in and through a particular work of art. While such trade-offs are not in themselves problematic, they still attest to the importance to retain a critical awareness of the possible contradictions between a works attitude and its concrete positionality within socio-political and economic vectors of power also in relation to the X-Border Art Biennial and its embedding in the Barents Euro-Arctic Region. By strictly adhering to the rules imposed by Russian authorities curators and artists at once made it possible to cross into an 
area previously inaccessible to visitors, while at the same time maintaining the smooth functioning of the overall border regime that limits the mobility of particular subjects at the border of the city and the state.

\section{Borders, art, and intervention: A conclusion}

Bordering practices take place on various registers of intersubjectivity from the nuclear family, via peer groups, virtual online communities, and up to the nation-state and supra-national entities such as the Barents Euro-Arctic Region. State borders are constituted, articulated, and negotiated on a material, performative, and cognitive register at once. As the present article has argued, cultural expressions and aesthetics play an important role in these processes. The material forms and formal properties of for instance barbed wire fences, walls, and passage ways invite for certain dominant performances that, in vernacular day-to-day practice, interpret and potentially rearticulate them on the basis of established procedures, and familiar interpretative schemata and cognitive frames. The 'correct' application of these dominant procedures, schemata, and frames is facilitated through the availability of intersubjective paradigm scenarios that reiterate generic knowledge regarding the correct performance and articulation of dominant subject-positions.

Works of art can play a crucial role in drawing attention to the ultimate contingency of such reified regimes of bordering in that they can de-habitualise established frames for perception and cognition. As such, art can contribute to a "reconfiguration of the sensible" in the sense of Rancière (2010: 141) that undermines established notions of "commonsense" (141) and entails critical potentials for subversive agency and political change (Amilhat Szary, 2012; Schimanski and Wolfe 2013; Schimanski, 2014). With reference to readings of artworks that were displayed during the X-Border Art Biennial, the present article has argued that a neo-formalist approach can help to identify the formal elements that invite such potentially subversive acts of seeing and thinking at the contemporary dis-located and de-territorialized border.

On the other hand, however, works of art always operate and function within the frames of concrete socio-economic and political power-vectors (Paglen and Gach 2003). Artistic and curatorial practices are, as such, in constant danger of falling prey to the very economic and political interests they intend to discursively challenge but often remain dependent upon at an underlying level. From an implicit enlistment in place branding projects that employ art for the purpose of a superficial "surface aestheticization" (Welsch 1997: 3) to attract global attention and tourism flows, via a co-optation of art shows to mould artists and spectators into post-industrial consumer identities, to the unintended facilitation of operational functions in inter-state border regimes, the practices of artists and curators are ridden by ambivalences and contradictions that have to be carefully assessed and negotiated. As a result, artistic and curatorial practices emerge as neither inherently liberating and empowering, nor essentially selfserving and co-opted, but as ambiguously positioned by various and changing interests and socio-political as well as cultural and material constraints.

\section{Acknowledgement}


Research for this article has been funded by the European Commission through the FP 7 project EUBORDERSCAPES (project number 290775). I would like to extend my gratitude to Anne Laure Amilhat Szary for her constructive feedback on an earlier draft of this article.

\section{References}

Amilhat Szary, A. L. 2012. Walls and Border Art: The Politics of Art Display. Journal of Borderlands Studies 27(2): 213-228.

Amoore, L. and A. Hall. 2010. Border Theatre: On the Arts of Security and Resistance. Cultural Geographies 17(3): 299-319.

Beer, D. 2013. Genre, Boundary Drawing and the Classificatory Imagination. Cultural Sociology, 7(2): 145-160.

Brambilla, C. 2010. Pluriversal Citizenship and Borderscapes. In Transient Spaces. The Tourist Syndrome, ed. M. Sorbello and A. Weitzel , 61-65. Berlin: Argobooks.

Brambilla, C. 2014. Exploring the Critical Potential of the Borderscapes Concept, Geopolitics, DOI: dx.doi.org/10.1080/14650045.2014.884561

Buden, B. 2006. What is Political in the Art of Milovan Destil Markovic? Transfigurative Works. 1995-2006, ed. M. D. Markovic, 7-9. Nürnberg: Verlag für Moderne Kunst.

De Duve, T. 2007. The Glocal and the Singuniversal. Third Text 21(6): 681-688.

Dimitrakaki, A. 2012. Art, Globalisation and the Exhibition Form. Third Text 26(3): 305-319.

Greve, A. 2015. Fiction as a Source of Self-Knowledge: Cognitive Narratology Faces the Demands of Franz Kafka. Knowledge Cultures (forthcoming).

Gustafsson, H. 2013. Foresight, Hindsight and State Secrecy in the American West: The Geopolitical Aesthetics of Trevor Paglen. Journal of Visual Culture 12(1): 148-164.

Hønneland, G. 2010. East-West Collaboration in the European North: Structures and Perceptions. International Journal 65(4): 837-850.

Hønneland, G. 1998. Identity Formation in the Barents Euro-Arctic Region. Cooperation \& Conflict 33(3): 277-297.

Houtum, H. and T. Naerssen. 2002. Bordering, Ordering and Othering. Tijdschrift voor Economische en Sociale Geografie 93(2): 125-136.

Houtum, H. 2012. Remapping Borders. In A Companion to Border Studies, ed. T. M. Wilson and H. Donnan, 405-417. Oxford: Blackwell. 
Johnson, C., R. Jones, A. Paasi, L. Amoore, A. Mountz and C. Rumford. 2011. Interventions on Rethinking 'the Border' in Border Studies. Political Geography 30: 61-69.

Kirschner, S. R. 2010. Sociocultural Subjectivities: Progress, Prospects, Problems. Theory \& Psychology 20(6): 765-780.

Kirschner, S. R. and J. Martin. 2012. The Sociocultural Turn in Psychology: An Introduction and an Invitation. In The Sociocultural Turn in Psychology: The Contextual Emergence of Mind and Self, ed. S.R. Kirschner and J. Martin, 1-27. New York: Columbia UP.

Kompatsiaris, P. 2014. Curating Resistance: Ambivalences and Potentials of Contemporary Art Biennials. Communication, Culture, \& Critique 7: 76-91.

Nielsen, J. P. 1994. The Barents Region in Historical Perspective. In The Barents Region: Regional Cooperation in Arctic Europe, ed. O. Schram Stokke and O. Tunander, 87-100. London: Sage.

O’Dowd, L. 2010. From a 'Borderless World' to a 'World of Borders': Bringing History Back In. Environment \& Planning: D 28(6): 1031-1050.

Paglen, T. 2014. New Photos of the NSA and Other Top Intelligence Agencies Revealed for the First Time. The Intercept. https://firstlook.org/theintercept/article/2014/02/10/new-photos-of-nsa-andothers/.

Paglen, T. 2010. Blank Spots on the Map: The Dark Geography of the Pentagon's Secret World. New York: New American Library.

Paglen, T. and A. Gach. 2003. Tactics Without Tears. The Journal of Aesthetics and Protest. 1(2), http://www.joaap.org/1/TacticsWithout/index.html.

Parker, N. and N. Vaughan-Williams. 2009. Lines in the Sand? Towards an Agenda for Critical Border Studies. Geopolitics 14(3): 582-587.

Perkins, C. and C. Rumford. 2013. The Politics of (Un)fixity and the Vernacularisation of Borders. Global Society 27(3): 267-282.

Rajaram, P. K. and C. Grundy-Warr. 2007. Introduction. In Borderscapes: Hidden Geographies and Politics at Territory's Edge, ed. P. K. Rajaram and C. Grundy-Warr, ix-xl. Minneapolis: University of Minnesota Press.

Ranciére, J. 2010. Dissensus: On Politics and Aesthetics. London: Continuum.

Rovisco, M. 2010. Reframing Europe and the Global: Conceptualizing the Border in Cultural Encounters. Environment \& Planning D 28(6): 1015-1030.

Rumford, C. 2012. Towards a Multiperspectival Study of Borders. Geopolitics 17(4): 887-902.

Schimanski, J. 2014. Border Aesthetics and Cultural Distancing in the Norwegian-Russian Borderscape. Geopolitics doi: $\underline{10.1080 / 14650045.2014 .884562 .}$. 
Pötzsch, Art Across Borders

Schimanski, J. and S. Wolfe. 2013. The Aesthetics of Borders. In Assigning Cultural Values, ed. K. Aukrust, 235-250. Frankfurt a.M.: Peter Lang.

Schmidt, S. J. 2008. Operative Fictions, or: How to Talk About Society. Constructivist Foundations 3(2): 67-68.

Thompson, K. 1988. Breaking the Glass Armor. Neoformalist Film Analysis. Princeton: Princeton UP.

Vukov, T. and M. Sheller. 2013. Borderwork: Surveillant Assemblages, Virtual Fences, and Tactical Countermedia. Social Semiotics 23(2): 225-241.

Walsh, J. 2013. Remapping the Border: Geospatial Technologies and Border Activism. Environment \& Planning D 31: 969-987.

Weber, C. 2012. Design, Translation, Citizenship: Reflections on the Virtual (De)territorializing of the US - Mexico Border. Environment \& Planning D: 482-496.

Welsch, W. 1997. Undoing Aesthetics. London: Sage.

X-Border Art Biennial. 2013. X-Border Art Biennial website. www.Xborder.info.

Zerubavel, E. 1997. Social Mindscapes. An Invitation to Cognitive Sociology. Harvard: Harvard UP. 